Portland State University

PDXScholar

\title{
Interest in Nonsurgical Female Permanent Contraception Among Men in Portland, Oregon and Eastern Maharashtra, India
}

\author{
Elizabeth K. Harrington \\ Oregon Health \& Science University \\ Diane Gordon \\ Oregon National Primate Research Center \\ Pramod Bahulekar \\ Mahatma Gandhi Institute of Medical Sciences \\ B.S. Garg \\ Oregon Health \& Science University \\ Isabel Osgood-Roach \\ Oregon Health \& Science University

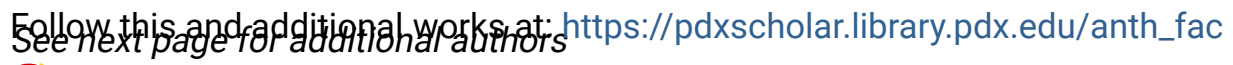 \\ Part of the Anthropology Commons \\ Let us know how access to this document benefits you.
}

\section{Citation Details}

Harrington, E. K., Gordon, D., Bahulekar, P., Garg, B. S., Osgood-Roach, I., Jensen, J. T., \& Aengst, J. (2015). Interest in nonsurgical female permanent contraception among men in Portland, Oregon and eastern Maharashtra, India. Contraception.

This Post-Print is brought to you for free and open access. It has been accepted for inclusion in Anthropology Faculty Publications and Presentations by an authorized administrator of PDXScholar. Please contact us if we can make this document more accessible: pdxscholar@pdx.edu. 
Authors

Elizabeth K. Harrington, Diane Gordon, Pramod Bahulekar, B.S. Garg, Isabel Osgood-Roach, Jeffrey T. Jensen, and Jennifer Aengst 


\section{Title}

Interest in nonsurgical female permanent contraception among men in Portland, Oregon and eastern Maharashtra, India

\section{Authors names and affiliations}

Elizabeth K. Harrington ${ }^{1}$, Diana Gordon ${ }^{2}$, Pramod Bahulekar ${ }^{3}$, B.S. Garg, Isabel

Osgood-Roach $^{1}$, Jeffrey T. Jensen ${ }^{1,2}$, Jennifer Aengst ${ }^{1,4}$

${ }^{1}$ Oregon Health \& Science University

Department of Obstetrics \& Gynecology

Mail code L466

3181 SW Sam Jackson Park Rd

Portland, OR 97239

Phone: 5034948211

Fax: 5034945680

harringe@ohsu.edu - *Corresponding author isabelosgoodroach@gmail.com jensenje@ohsu.edu jaengst@pdx.edu

${ }^{2}$ Oregon National Primate Research Center 1505 NW 185th Ave

Beaverton, OR 97006

gordondi@ohsu.edu

${ }^{3}$ Mahatma Gandhi Institute of Medical Sciences

Sevagram, Wardha 442102

Maharashtra, India

+91 7152 284341-55

pramod.bahulekar@gmail.com

gargbs@gmail.com

${ }^{4}$ Portland State University

Department of Anthropology

P.O. Box 751

Portland, OR 97207

jaengst@pdx.edu 


\begin{abstract}
Objective: We examined the men's attitudes and perceptions toward the concept of nonsurgical female permanent contraception (NSPC), or novel approaches to permanent contraception (PC) that do not require incisions or surgical equipment/hysteroscope.
\end{abstract}

Study design: Cross-sectional survey of married/partnered men in Portland, OR and rural eastern Maharashtra, India. Descriptive analysis was performed.

Results: In India (N=150), most men (80\%) anticipated their partners would undergo PC in the future, compared to $30 \%$ in Portland $(\mathrm{N}=170)$. About a third $(39.6 \%$ in India, $82 \%$ in Portland) reported being uncomfortable with PC for partners due to the need for surgery. Most men (85\% in India, $82 \%$ in Portland) expressed a preference for a hypothetical new method of female NSPC over surgery, if safe and effective.

Conclusion: Most men sampled in two diverse settings expressed interest in NSPC for women.

Implications: Men's perceptions of new female contraceptive methods are important to the contraceptive development process. Men may find a safe and effective nonsurgical method of permanent female contraception more acceptable than surgical PC.

\title{
Keywords:
}

Sterilization, permanent contraception, perception, attitudes, men

\section{Word count:}

1292 (Introduction 250, Methods 316, Results 216, Discussion 510); Abstract 163 


\section{Introduction}

Over one third of reproductive-age women worldwide use female permanent contraception (PC), or sterilization, reflecting the critical role of female PC in the global contraceptive method mix [1]. It is the most prevalent method among women $>30$ year of age in the US [2], and is the most commonly used method in India at $38 \%$ of married women [3].

The development of novel approaches to female nonsurgical permanent contraception (NSPC) that are highly effective, low cost, single use, suitable for delivery by non-surgeons, and portable to rural settings may increase safety and access for women who desire no additional pregnancies. One such method, polidocanol foam, is currently under investigation at Oregon Health \& Science University (OHSU). The procedure involves foam insertion into the uterus via a small balloon catheter, and is currently being studied in the nonhuman primate model [4]. While the Essure ${ }^{\circledR}$ microinsert system does not involve an incision, it requires surgical equipment (e.g. hysteroscope, light source) and training, and is not considered a new method of NSPC.

Male partners are influential in women's contraceptive and reproductive health decision-making [5], and their perspectives are critical to the development of an acceptable and desirable new contraceptive method. Men and women have been shown to prioritize different contraceptive characteristics [6]. There are currently no published studies of men's perceptions of NSPC. We aimed to describe and gain insight into men's perceptions of NSPC in Portland, OR and eastern Maharashtra, India, and to generate hypotheses for future research on NSPC.

\section{Methods}

This study represents the survey portion of a larger dual-sited, mixed-methods perception study incorporating qualitative interviews with married/partnered women, focus group discussions with obstetrician-gynecologists (OB/GYNs), and a survey with men. Surveys were administered in Portland, OR from August-October 2013, and in eastern Maharashtra, Wardha District from January-February 2014. The study was approved by the institutional review boards at Oregon Health \& Science University (OHSU; Portland, OR) and the Mahatma Gandhi Institute of Medical Sciences (MGIMS; 
Sevagram, India). The two sites were chosen based on the locations of OHSU and its academic collaborator, MGIMS, and were designed to provide initial perspectives from two diverse settings where surgical female PC is widely used. This study was descriptive and hypothesis-generating in purpose, and thus was not powered to address any a priori hypotheses.

We administered a 12-question survey collecting no identifying information to a convenience sample of men (survey questions available in supplemental material). Inclusion criteria were age 18-45 years, English/Spanish-speaking (Portland) or Marathispeaking (India), married or partnered with a woman, and having at least 1 child. The recruitment strategies differed greatly by site. In India, men were recruited from 3 villages in person by MGIMS male social workers, and were approached both in primary care clinic waiting rooms and in the community at their homes or on the street. All surveys in India were verbally administered. Men in Oregon were recruited in person by a research assistant in OHSU primary care and women's health clinic waiting rooms, as well as electronically via email (using the OHSU Women's Health Research Unit listserve) and social marketing sites. All men in the Oregon sample took the survey in a written (paper or electronic) form, though literacy was not an inclusion criterion. The survey did not provide any description of what a nonsurgical method of female PC would entail. Data were managed in RedCap, and were analyzed with descriptive statistics.

\section{Results}

The demographic characteristics for each sample are shown in Table 1. The majority of participants in Portland (64.9\%, N=150) and India (58.4\%, N=170) did not desire additional children. Respondents' mean age was 35.9 in Portland, and 34.1 in India. Most men in both samples were married and had 1-2 children; 27\% versus 5.4\% of men in Oregon and India, respectively, had 3-4 children. Current use of vasectomy was reported by $18.9 \%$ of participants in Portland and $0.7 \%$ in India, and $9.5 \%$ and $22.8 \%$, respectively, reported their partners had undergone tubal sterilization.

Among men whose partners were at risk for pregnancy, $80 \%$ of men in India were considering pursuing female PC in the future compared with 30\% in Portland. However, when asked to consider whether they would prefer a vasectomy to their partner 
undergoing surgical sterilization, similar proportions (52\% in India and 55.4\% in Portland) agreed or strongly agreed with the statement "I would prefer to have a vasectomy." A total of $39.6 \%$ participants in India and $30.1 \%$ in Portland reported being uncomfortable with PC for their partners due to the need for surgery. Most men at both sites (85\% in India, $82 \%$ in Portland) reported a preference for a new method of NSPC over surgery, if safe and effective. Figure 1 summarizes these findings.

\section{Discussion}

This cross-sectional study of over 300 men in two diverse samples investigated perceptions of male and female PC, and nonsurgical female PC. A substantial proportion of men in each sample were considering PC for themselves or their female partners in the future, which is consistent with the high prevalence of PC in both the U.S. and India.

While far more men in the Portland sample (19\%) than the India sample $(0.7 \%)$ had undergone vasectomy, more than half of men in each sample stated they would prefer to have a vasectomy rather than their female partners undergoing sterilization. This finding was not surprising among men sampled in Portland, who were predominantly white and college-educated - factors associated with use of vasectomy in the U.S. [7]. In rural Maharashtra, however, vasectomy prevalence was estimated at $3.2 \%$ in the last India National Family Health Survey [3], and female surgical sterilization is normalized. We found that $50 \%$ of Indian men in our study were considering future vasectomy, which suggests that our sample is not reflective of attitudes in the general population, or that social desirability biased men toward stating more open views on vasectomy.

The majority of men at both sites expressed interest in a nonsurgical permanent contraception method for women, and would prefer an alternative to surgery if it were available. Our study did not investigate the decision-making process around choosing male or female PC; prior studies suggest that there are likely multiple relationship, sociocultural, and financial factors involved [8-9]. Furthermore, we deliberately included men with personal and partner history of permanent contraception, but imagine that these individuals may have more favorable views of PC than the general population. Also, their positive and/or negative personal and partner experiences of surgical PC may alter their perceptions of NSPC for women. 
This study had several limitations. Given its descriptive aims and convenience sampling, results were not designed to be representative of broader populations. The two samples were not directly comparable, and a priori hypotheses were not tested. We felt that reporting on bivariate or multivariate statistics could lend a false sense of precision about our data, and that descriptive statistics were more appropriate for this exploratory study. The results are thus geared to provide support for future perception studies on NSPC. Surveys in India were done face-to-face, and social desirability bias could have affected men's responses as noted above. Finally, men were asked about the concept of NSPC only, and were not given details on the risks and benefits of a particular method, such as whether a method is immediately effective. Perceptions of a method that is actually available may diverge from perceptions of a hypothetical method.

In conclusion, this study provides initial insights into men's perceptions of PC and NSPC among two diverse samples. Overall, respondents demonstrated a strong preference for a nonsurgical alternative PC method for women both in Portland and in India. Further hypothesis-driven research is needed to understand men's perspectives on NSPC in representative populations, as well as to understand characteristics of decisionmaking within couples around male and female PC.

\section{Acknowledgements}

The authors acknowledge the staff at the OHSU Center for Women's Health, the study staff at MGIMS who administered the survey in India, and Dr. Poonam Verma Shivkumar for her advisory support. We also thank the OHSU Women's Health Research Unit for regulatory and technical support. This study was supported by the Bill \& Melinda Gates Foundation, Global Development Grants OPP1060424, OPP1084270. 


\section{References}

[1] United Nations, Department of Economic and Social Affairs, Population Division. World Contraceptive Use 2010 (POP/DB/CP/Rev2010). 2011; Accessed Mar 12013 : http://www.un.org/esa/population/publications/wcu2010/Main.html.

[2] Mosher WD, Jones J. Use of contraception in the United States: 1982-2008. Vital Health Statistics 2010;23:1-4.

[3] National Family Health Survey, 2007 (NFHS-3) 2005-06. India: Volume 1. Mumbai: IIPS (International Institute for Population Sciences)

[4] Jensen JT, Hanna C, Yao S, Micks E, Edelman A, Holden L, et al. Blockade of tubal patency following transcervical administration of polidocanol foam: initial studies in rhesus macaques. Contraception 2014;89:540-9.

[5] Dudgeon MR, Inhorn MC. Men's influences on women's reproductive health: medical anthropological perspectives. Social Science \& Medicine 2004;59:1379-95. [6] Grady WR, Klepinger DH, Nelson-Wally A. Contraceptive characteristics: the perception and priorities of men and women. Family Planning Perspectives 1999;31:16875.

[7] Anderson JE, Warner L, Jamieson DJ, Kissin DM, Nangia AK, Macaluso M. Contraceptive sterilization use among married men in the United States: results from the male sample of the National Survey of Family Growth. Contraception 2010;82:230-5. [8] Anderson JE, Jamieson, DJ, Warner L, Kissin DM, Nangia AK, Maculuso M. Contraceptive sterilization among married adults: National data on who chooses vasectomy and tubal sterilization. Contraception 2010;85:552-57.

[9] Landry E, Ward V. Perspectives from couples on the vasectomy decision: A sixcountry study. In: Beyond Acceptability: Users' Perspectives on Contraception. Sundari Ravindran TK, Berer M, Cottingham J, editors. Reproductive Health Matters for the World Health Organization; 1997. 
Table 1: Demographic Characteristics

\begin{tabular}{|c|c|c|}
\hline & Portland $(n=170)$ & India $(n=150)$ \\
\hline Age & 35.9, median 36 & 34.1 , median 34 \\
\hline \multicolumn{3}{|l|}{ Number of children } \\
\hline 1 & $54(31.8 \%)$ & $75(50.3 \%)$ \\
\hline 2 & $70(41.2 \%)$ & $66(44.3 \%)$ \\
\hline 3 & $30(17.6 \%)$ & $8(5.4 \%)$ \\
\hline $4+$ & $16(9.4 \%)$ & 0 \\
\hline Family complete & $109(64.9 \%)$ & $87(58.4 \%)$ \\
\hline \multicolumn{3}{|l|}{ Marital status } \\
\hline Married & $133(78.7 \%)$ & $150(100 \%)$ \\
\hline \multicolumn{3}{|l|}{ Education } \\
\hline Primary or less & - & $23(15.4 \%)$ \\
\hline Secondary/Some college & $68(40 \%)$ & $82(55 \%)$ \\
\hline College degree or more & $118(60 \%)$ & $44(29.5 \%)$ \\
\hline \multicolumn{3}{|l|}{ Religion: US } \\
\hline Christian & $45(26.4 \%)$ & \\
\hline Other & $36(21.1 \%)$ & \\
\hline None & $89(52.4 \%)$ & \\
\hline \multicolumn{3}{|l|}{ Religion: India } \\
\hline Hindu & & $117(78.5 \%)$ \\
\hline Buddhist & & $22(14.8 \%)$ \\
\hline Muslim & & $9(6 \%)$ \\
\hline Other & & $1(0.7 \%)$ \\
\hline \multicolumn{3}{|l|}{ Race/ethnicity: US } \\
\hline White & $138(81.7 \%)$ & \\
\hline Latino & $13(7.7 \%)$ & \\
\hline Asian & $5(3 \%)$ & \\
\hline African-American & $3(1.8 \%)$ & \\
\hline Other & $10(5.9 \%)$ & \\
\hline \multicolumn{3}{|l|}{ Caste: India } \\
\hline Open & & $11(7.4 \%)$ \\
\hline Scheduled tribes & & $40(26.8 \% 0$ \\
\hline Scheduled castes & & $12(8.1 \%)$ \\
\hline Other backward classes & & $74(49.7 \%)$ \\
\hline Other & & $128.1 \%)$ \\
\hline Female partner PC use & $30(17.8 \%)$ & $34(22.8 \%)$ \\
\hline Personal history of vasectomy & $32(18.9 \%)$ & $1(0.7 \%)$ \\
\hline
\end{tabular}


Figure 1: Perception data on male PC, female PC, and NSPC

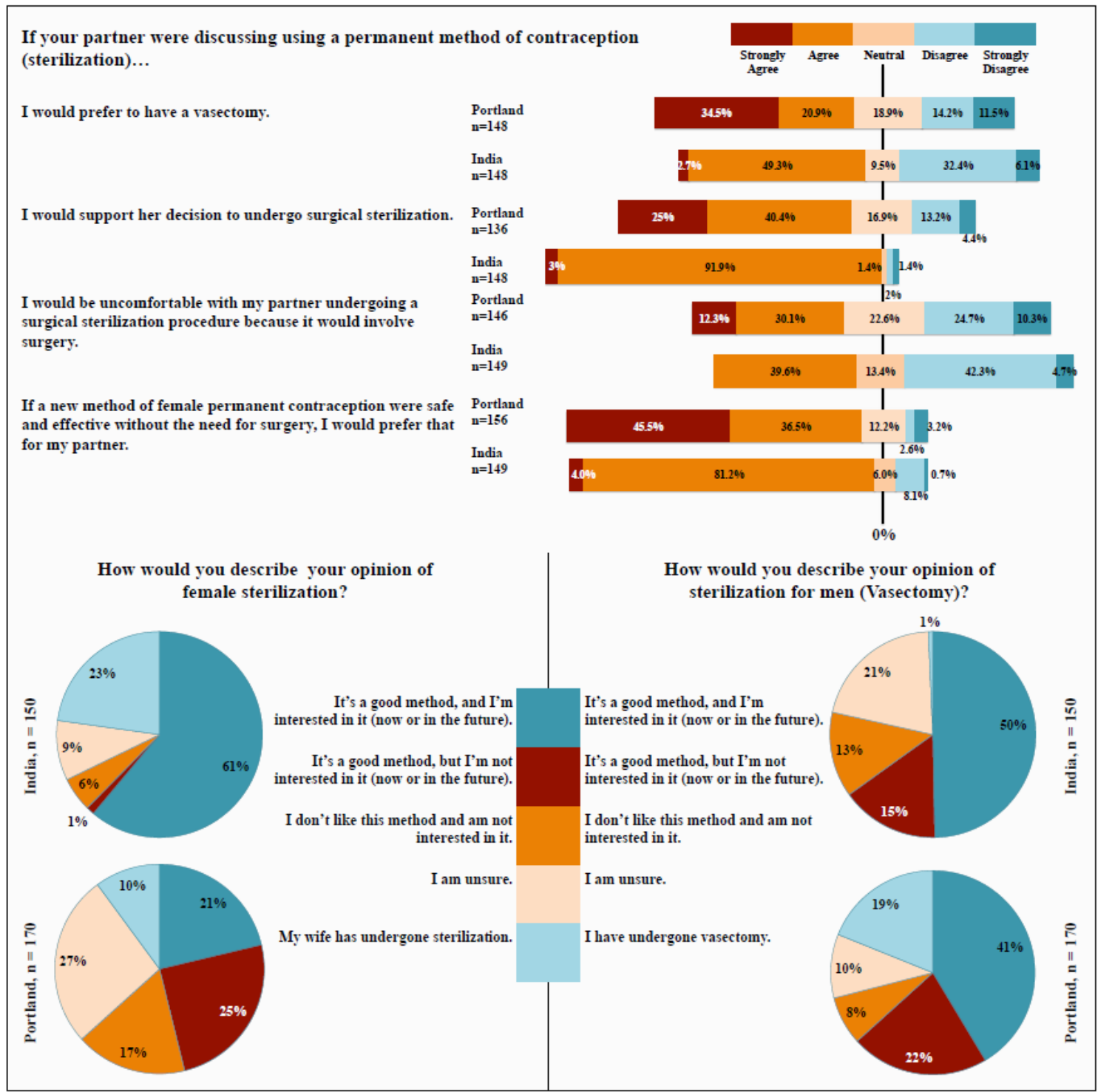

